\title{
Ativismo judicial e a coletivização de ação individual $^{*}$
}

\section{Judicial activism and the collectivization of individual action}

\section{Resumo}

O presente artigo enquadra-se no campo dedicado a análise crítica do que se convencionou denominar judicialização das políticas públicas. O método de que se valerá o presente artigo é o descritivo quanto ao problema com vistas a propor uma alteração legislativa com vistas a propiciar ao juiz uma visão global acerca dos impactos de sua decisão em determinada política pública. O objetivo, então, é demonstrar que a lógica individual na qual se baseia o processo é incompatível com a lógica consequencialista que a intervenção em determinada política pública exige. Com isso, propor-se-á a possibilidade de "coletivização" de ações individuais que tenham impacto em políticas públicas, sendo que tal proposta não está prevista no Código de Processo Civil em discussão no Congresso Nacional.

Palavras-chave: Políticas públicas. Poder judiciário. Novo instrumento processual.

\begin{abstract}
This article falls within the field dedicated to critical analysis of what is usually called the judicialization of public policy. The method that this article is worth the descriptive about the problem with a view to proposing a legislative amendment in order to provide the court with an overview of the impacts of their decisions on specific public policy. The goal, then, is to demonstrate that the individual logic in which the process is based is incompatible with consequentialist logic that intervention in specific public policy requires. Thus, the possibility of "collectivization" of individual actions that impact public policy, and that such a proposal is not in the Code of Civil Procedure in discussion in Congress will propose herself.
\end{abstract}

Keywords: Publics policy. Judiciary. New proceduaral tool. 


\section{Breve contextualização temática}

O termo ativismo judicial carece de uma interpretação uniforme. Todavia, para os fins do presente trabalho, o termo será considerado com vistas a identificar a atuação do Poder Judiciário que complementa ou corrige uma determinada política pública estabelecida pelo Poder Executivo, baseado na interpretação decorrente da Constituição.

Segundo Virgílio Afonso da Silva ${ }^{1}$ um dos problemas do ativismo está na lógica credor-devedor, própria do sistema liberal, que orienta as decisões judiciais a respeito do assunto. Afirma que o ativismo, dito "despreparado", acaba por ordenar, por exemplo, a disponibilização de medicamentos e ou tratamentos, sem levar em conta a política pública já estabelecida, ou seja, sem levar em conta o cenário global do problema.

Daí que, diante da provocação do Autor, que sugere ao Judiciário que faça uma análise global da situação quando analisa determinada política pública, é que surgiu a motivação para o presente artigo.

Veja que desde muito o Superior Tribunal de Justiça $^{2}$, bem como o Supremo Tribunal Federal ${ }^{3}$ já admitem a intervenção judicial nas políticas públicas, especialmente as relacionadas a fornecimento de medicamentos, então, não se refutará essa possibilidade, nem é objetivo do presente artigo definir os parâmetros para essa decisão.

Assim, a questão que se apresenta é: Como viabilizar, processualmente, a visão global sugerida pelo Autor para que o Juiz possa analisar/complementar a política pública levada a juízo.

Inicialmente, há que se asseverar que há uma inegável dificuldade em estabelecer, em tese, quais seriam os requisitos que autorizariam a intervenção do Judiciário na concretização de Políticas Públicas. Muitas são as iniciativas de justificar e delimitar atuação do Poder

2 SILVA, Virgílio Afonso da. O Judiciário e as políticas públicas: entre transformação social e obstáculo à realização dos direitos sociais. In: SOUZA NETO, Cláudio Pereira de; SARMENTO, Daniel. (Org.). Direitos sociais: fundamentação, judicialização e direitos sociais em espécies. Rio de Janeiro: Lúmen Júris, 2008. p. 587-599. Disponível em: $<$ http://www.teoriaedireitopublico.com.br/pdf/2008-Judiciario_e_politicas_publicas.pdf $>$. Acesso em: 24 jun. 2015.

3 [...] 1. A ordem constitucional vigente, em seu art. 196, consagra o direito à saúde como dever do Estado, que deverá, por meio de políticas sociais e econômicas, propiciar aos necessitados não "qualquer tratamento", mas o tratamento mais adequado e eficaz, capaz de ofertar ao enfermo
Judiciário, na análise de políticas públicas. Apenas para exemplificar, para Carlos Pereira de Souza Neto essa atuação seria delimitada da seguinte forma: 1) Circunscrito à esfera de fundamentabilidade material do Direito;

maior dignidade e menor sofrimento. 2. Sobreleva notar, ainda, que hoje é patente a idéia de que a Constituição não é ornamental, não se resume a um museu de princípios, não é meramente um ideário; reclama efetividade real de suas normas. Destarte, na aplicação das normas constitucionais, a exegese deve partir dos princípios fundamentais, para os princípios setoriais. E, sob esse ângulo, merece destaque o princípio fundante da República que destina especial proteção a dignidade da pessoa humana. 3. Sobre o tema não dissente o Egrégio Supremo Tribunal Federal, consoante se colhe da recente decisão, proferida em sede de Agravo Regimental na Suspensão de Segurança 175/CE, Relator Ministro Gilmar Mendes, julgado em 17.3.2010, cujos fundamentos se revelam perfeitamente aplicáveis ao caso sub examine, conforme noticiado no Informativo 579 do STF, 15 a 19 de março de 2010[...] STA 175 AgR/CE, rel. Min. Gilmar Mendes, 17.3.2010. 4. Last but not least, a alegação de que o impetrante não demonstrou a negativa de fornecimento do medicamento por parte da autoridade, reputada coatora, bem como o desrespeito ao prévio procedimento administrativo, de observância geral, não obsta o deferimento do pedido de fornecimento dos medicamentos pretendidos, por isso que o sopesamento dos valores em jogo impede que normas burocráticas sejam erigidas como óbice à obtenção de tratamento adequado e digno por parte de cidadão hipossuficiente. [...] 7. Ademais, o fato de o relatório e a receita médica terem emanado de médico não credenciado pelo SUS não os invalida para fins de obtenção do medicamento prescrito na rede pública, máxime porque a enfermidade do impetrante foi identificada em outros laudos e exames médicos acostados aos autos (fls.26/33), dentre eles, o exame "pesquisa qualitativa para vírus da Hepatite C (HCV)" realizado pelo Laboratório Central do Estado, vinculado à Secretaria Estadual de Saúde do Estado do Paraná, o qual obteve o resultado "positivo para detecção do RNA do Vírus do HCV” (fl. 26). 8. Recurso Ordinário provido, para conceder a segurança pleiteada na inicial, prejudicado o pedido de efeito suspensivo ao presente recurso (fls. 261/262), em razão do julgamento do mérito recursal e respectivo provimento. BRASIL. Superior Tribunal de Justiça. Recurso em Mandado de Segurança. RMS N 24.197. Primeira Turma. Recorrente: Ministério Público do Estado do Paraná. Recorrido: Estado do Paraná. Relator: Min. Luiz Fux. Brasília, 04 de maio de 2010. Disponível em: <http:/www.tjsp.jus.br/Download/EPM/ pdf/STJ-Fornecimentomedicamentos-hepatite-prescricaoparticular.pdf $>$. Acesso em: 24 jun. 2015.

4 BRASIL. Supremo Tribunal Federal. Medida Cautelar em Arguição de Descumprimento de Preceito Fundamental. ADPF 45 MC/DF. Plenário. Agravante: Partido da Social Democracia Brasileira. Agravado: Presidente da República. Relator: Min. Celso de Mello. Brasília, 29 de abril de 2004. Disponível em: <http://stf.jusbrasil.com.br/jurisprudencia/14800508/medida-cautelar-em-arguicao-de-descumprimento-de-preceito-fundamental-adpf-45-df-stf $>$. Acesso em: 24 jun. 2015. 
2) Restrita a defesa dos hipossuficientes; 3 ) Deve ter em vista a universalização da medida; 4) Deve ainda priorizar a opção técnica da administração e também a solução mais econômica ${ }^{5}$.

A despeito desses parâmetros, o que normalmente acontece é que o juiz, ao ser apresentado a um problema individual, a exemplo da falta de acesso a determinado medicamento/tratamento de alto custo, muitas vezes defere o pedido sem levar em conta, ou mesmo, sem ter condições fáticas e técnicas de levar em conta o caráter global da questão.

Daí, vem a questão que já se mencionou: Como viabilizar que o juiz tenha a referida visão global? Ou seja, é possível "coletivizar" uma ação individual que busque corrigir/complementar determinada política pública?

\section{Da proposta do presente artigo}

A proposta que se pretende analisar no presente trabalho é: Com base no atual sistema processual, seria possível coletivizar uma ação individual que busca a interferência em determinada política pública - a exemplo, da disponibilização de tratamento de saúde ou medicamento - perante o mesmo juiz?

Inicialmente, devemos ilustrar o tipo de problema judicial de que esta se tratando. Ajuizada uma ação individual que busca determinado medicamento ou tratamento de saúde não previsto na política pública, essa ação poderia vir a englobar todos aqueles que estejam na mesma situação?

Diante de uma situação que possivelmente atinge outros cidadãos, a atuação do Poder Judiciário, que garante o direito a um único indivíduo, o acesso ao bem ou direito padece de algumas críticas, girando em torno do princípio da isonomia, entre elas: 1) Conferir o pedido a esta pessoa pode levar ao desprestígio daquele que não foi ao Judiciário que, eventualmente, esteja em situação pior; ou 2) O desprestígio a outras políticas públicas igualmente relevantes. Mas, ainda sim, deve-se questionar: Como mudar essa situação?

Como se sabe, as opções originariamente conferi-

SOUZA NETO, Cláudio Pereira. A justiciabilidade dos direitos sociais: críticas e parâmetros. In: SOUZA NETO, Cláudio Pereira de; SARMENTO, Daniel (Org.). Direitos sociais: fundamentos, judicialização e direitos sociais em espécie. Rio de Janeiro: Lumen Juris, 2008. p. 515-551. das são: $\mathrm{O}$ ajuizamento de outras ações individuais pelos respectivos interessados ou o ajuizamento de uma ação coletiva.

Se a ação a ser ajuizada for de natureza coletiva, o juiz da causa mais facilmente poderá ter acesso a visão global do fato.

Nesse caso, a possibilidade de indivíduo representar interesse coletivo não é nova no direito comparado. Basta lembrar as relator actions e as class actions da commom law sintetizadas da seguinte forma por Ada Pelegrine Grinover:

Não se podem deixar de lado, nesse rápido esboço da experiência estrangeira, instrumentos tradicionais, a que se deu novo conteúdo, no quadro de common law: é o caso dos "relator actions" e, mais ainda, das "class actions". As primeiras, de uso comum na Inglaterra e na Austrália, permitem que, na inércia do "attorney general", o indivíduo ou uma associação privada aja em juízo em nome, com a autorização e sob o controle do "attorney general", ainda que o indivíduo ou o grupo não tenha legitimação própria. Os exemplos mais freqüentes são os de "public nuisance", em que a coletividade sofre um prejuízo em sua saúde e os de edificações irregulares. Os efeitos do provimento jurisdicional beneficiam a toda a coletividade. Quanto às "class action", sua importância tornou-se transcendental, especialmente nos Estados Unidos. Aqui também estamos diante de um instituto tradicional, inspirado na "equity": mas o autor (ou "class suitor") não necessita de autorização do "attorney general" ou de qualquer outro órgão oficial. Os controles sobre sua ação, que também existem, são exercidos essencialmente pelo juiz. Tratando-se de membro de uma "classe", que age no interesse dessa mesma classe, os efeitos (positivos ou negativos) da sentença valem com relação a todos os membros da categoria. São conhecidos os casos em que um único indivíduo ou uma associação agiu para tutelar interesses de milhares de pessoas, freqüentemente não identificáveis, na defesa de "civil rights" (v.g., contra discriminações raciais ao nível de emprego, educação, habitação), do ambiente dos direitos do consumidor e do pequeno investidor, etc ${ }^{6}$.

Todavia, como se sabe, o Direito Brasileiro não confere, como regra, a legitimidade ao cidadão para proteger interesse de natureza coletiva. A exceção ficaria por conta da Ação Popular7, sendo que, nessa ação, há a pos-

6 GRINOVER, Ada Pellegrini. A tutela jurisdicional dos interesses difusos. Revista Brasileira de Direito Processual: RBDPro, Uberaba, v. 15, n. 59, p. 23-47, jul./set. 2007.

7 A ação popular é um instrumento de defesa dos interesses da coletividade, utilizável por qualquer de seus membros. Por ela 
sibilidade de ingresso do ente coletivo em ação originariamente ajuizada por indivíduo, nos termos do artigo $9^{\circ}$ da Lei $4.717 / 65^{8}$.

O problema está nas ações judiciais individuais, que não se enquadram, legalmente, no conceito de interesse difuso, coletivo ou individual homogêneo ${ }^{9}$, pois nestas, dificilmente, será conferida ao Juiz uma visão global da situação.

E qual seria a proposta? Instaurar o denominado incidente de coletivização da demanda individual especialmente para os casos em que se busque corrigir ou complementar política pública definida pelo Governo.

Diferente do caso da ação popular, em que se exige a desistência por parte do cidadão para o ingresso do substituto, o que se propõe na presente reflexão seria uma forma de coletivização de uma ação individual, ou seja, refletir a respeito da possibilidade de lege ferenda de que uma ação originariamente ajuizada, que não se enquadra no conceito de interesse coletivo pudesse ter seus limites subjetivos ampliados para englobar todos aqueles que estivessem na mesma situação fática.

não se amparam direitos individuais próprios, mas sim interesses da comunidade. $\mathrm{O}$ beneficiário direto e imediato desta ação não é o autor; é o povo, titular do direito subjetivo ao governo honesto. MEIRELLES, Hely Lopes. Mandado de segurança. 28. ed. São Paulo: Malheiros, 2005. p. 130.

8 Art. $9^{\circ}$ Se o autor desistir da ação ou der motiva à absolvição da instância, serão publicados editais nos prazos e condições previstos no art. $7^{\circ}$, inciso II, ficando assegurado a qualquer cidadão, bem como ao representante do Ministério Público, dentro do prazo de 90 (noventa) dias da última publicação feita, promover o prosseguimento da ação. BRASIL. Lei no 4.717, de 29 de junho de 1965. Regula a ação popular. Disponível em: <http://www.planalto.gov. br/ccivil_03/LEIS/L4717.htm>. Acesso em: 24 jun. 2015.

9 No caso Brasileiro, a definição desses direitos está prevista no Código de Defesa do Consumidor, Lei 8.078/90: Art. 81. A defesa dos interesses e direitos dos consumidores e das vítimas poderá ser exercida em juízo individualmente, ou a título coletivo. Parágrafo único. A defesa coletiva será exercida quando se tratar de: I - interesses ou direitos difusos, assim entendidos, para efeitos deste código, os transindividuais, de natureza indivisível, de que sejam titulares pessoas indeterminadas e ligadas por circunstâncias de fato; II - interesses ou direitos coletivos, assim entendidos, para efeitos deste código, os transindividuais, de natureza indivisível de que seja titular grupo, categoria ou classe de pessoas ligadas entre si ou com a parte contrária por uma relação jurídica base; III - interesses ou direitos individuais homogêneos, assim entendidos os decorrentes de origem comum. BRASIL. Lei no 8.078, de 11 de setembro de 1990. Dispõe sobre a proteção do consumidor e dá outras providências. Disponível em: <http://www.planalto.gov.br/ ccivil_03/leis/18078.htm>. Acesso em: 24 jun. 2015.
E, para começar a responder a presente questão, inicialmente, devemos identificar processualmente, a situação. Para tanto, algumas das questões a serem analisadas são as seguintes:

1) Entre todos aqueles que necessitam de tratamento de saúde ou medicamento podemos identificar um interesse decorrente de origem comum, a configurar interesse individual homogêneo a justificar uma ação civil pública?

2) As ações individuais que buscam tratamento de saúde ou medicamento no garantido pelo sistema universal seriam conexas, porque comuns as causas de pedir e/ou pedido?

3) Por fim, mesmo que não havendo conexão, haveria ao menos litisconsórcio entre os pleiteantes ao tratamento ou medicamento, dada a afinidade de questões por um ponto comum de fato ou de direito?

\section{Poderiam os autores de demandas que bus- cam determinado medicamento ou trata- mento de saúde serem reunidos em ação de natureza coletiva?}

Inicialmente, nota-se que a situação pela qual passa aquele Autor individual que busca determinado medicamento ou tratamento, não previsto pela política pública, pode ser comum a outros cidadãos.

Mas aí fica pergunta: Isso configuraria hipótese de direito individual homogêneo, pois decorrente de origem comum, nos termos do artigo 81, inciso III do Código de Defesa do Consumidor.

Art. 81. A defesa dos interesses e direitos dos consumidores e das vítimas poderá ser exercida em juízo individualmente, ou a título coletivo. [...] III - interesses ou direitos individuais homogêneos, assim entendidos os decorrentes de origem comum. ${ }^{10}$

Origem comum segundo a doutrina ocorre nos casos em que exista uma relevância social, seja inviável a formação de litisconsórcio e sejam comuns as questões de fato e de direito. ${ }^{11}$

BRASIL. Lei $n^{\circ}$ 8.078, de 11 de setembro de 1990. Dispõe sobre a proteção do consumidor e dá outras providências. Disponível em: <http://www.planalto.gov.br/ccivil_03/leis/ 18078.htm>. Acesso em: 24 jun. 2015.

11 RODRIGUES, Marcelo Abelha. Ação civil pública. In: DIDIER JR., Fredie (Org.). Ações constitucionais. 6. ed. Salvador: Jus Podivm, 2012. p. 351-446. p. 375. 
Assim, pelo que se nota, não se trata de interesse individual homogêneo, pois não há o caráter transindividual exigido pelo Código do Consumidor. Além disso, no caso do interesse individual homogêneo, um mesmo fato gera prejuízo para um número de indivíduos, por exemplo, um mesmo acidente que atinge determinado número de pessoas. No caso em que se apresenta, qual seja, a busca pelo tratamento médico ou medicamento, não se trata de repercussões diferentes do mesmo fato, mas sim fatos diferentes que se repetem. Ou seja, não se trata de uma negativa geral e irrestrita, mas sim de várias negativas a todos os pleiteantes.

Por outro lado, sabe-se, que muito embora não configure interesse individual homogêneo, a jurisprudência admite que o Ministério Público ajuíze ação civil pública na defesa de interesse individual indisponível ${ }^{12}$.

Nesse caso, parece claro, a atuação do Ministério

12 [...] 1. A Primeira Seção do Superior Tribunal de Justiça consolidou seu entendimento pela legitimidade do Ministério Público para ajuizar Ação Civil Pública "com o intuito de garantir fornecimento de prótese auditiva a portador de deficiência" (REsp 931.513/RS, Rel.p/ acórdão Min. HERMAN BENJAMIN, DJe 27/9/10). 2. Agravo não provido. BRASIL. Superior Tribunal de Justiça. Agravo Regimental no Recurso Especial. AgRg no REsp 1086805 RS 2008/0191648-9. Primeira Turma. Agravante: Estado do Rio Grande do Sul. Agravado: Ministério Publico do Estado do Rio Grande do Sul. Relator: Min. Arnaldo Esteves Lima. Brasilia, 02 de agosto de 2011. Disponível em: <http://stj.jusbrasil.com.br/jurisprudencia/21082652/ agravo-regimental-no-recurso-especial-agrg-no-resp1086805-rs-2008-0191648-9-stj/inteiro-teor-21082653>. Acesso em: 24 jun. 2015. [...]3. Constitui função institucional e nobre do Ministério Público buscar a entrega da prestação jurisdicional para obrigar o plano de saúde a custear tratamento quimioterápico em qualquer centro urbano, à menor, conveniado do recorrente. Assim, reconhece-se legitimidade ativa do Ministério Público para propor ação civil pública em defesa de direito indisponível, como é o direito à saúde, em benefício do hipossuficiente.4. A legitimação extraordinária, outorgada pela Constituição Federal (art. 127, caput e art. 129, III e X), pela Lei Orgânica do Ministério Público (art. 25, IV, da Lei 8.625/93) e pelo ECA (arts.201, V e 208, VII, da Lei 8.069/90), justifica-se pelo relevante interesse social e pela importância do bem jurídico a ser tutelado.5. Recurso especial não provido. (Grifo nosso). BRASIL. Superior Tribunal de Justiça. Embargos de Declaração no Recurso Especial. EDcl no REsp 976021 MG 2007/0185192-0. Terceira Turma. Recorrente: UNIMED Uberlândia Cooperativa de Trabalho Médico. Recorrido: Ministério Público do Estado de Minas Gerais. Relator: Min(a). Nancy Andrighi. Brasília, 26 de abril de 2011. Disponível em: <http://stj.jusbrasil.com.br/jurisprudencia/19095056/embargos-de-declaracao-no-recurso-especial-edcl-no-resp-976021-mg-2007-0185192-0/ inteiro-teor-19095057>. Acesso em: 24 jun. 2015.
Público se dá na função de representante judicial do indivíduo, da mesma forma que a Defensoria Pública.

Enfim, o problema que se apresenta é: Como conseguir que uma ação individual que busque corrigir complementar determinada política pública faculte ao Juiz uma visão global da questão, bem como reduza a possibilidade de redução do tratamento desigual daqueles que estão buscando comando judicial semelhante?

Dito isso, a proposta do presente artigo é sugerir a ampliação dos efeitos da coisa julgada in utilibus, típicos das ações coletivas, para sua aplicação também para quando o Ministério Público/Defensoria Pública ou Associação agissem na defesa de interesses individuais indisponíveis que exigissem a correção ou complementação de política pública questionada, no caso, a concessão de determinado medicamento ou tratamento.

Essa primeira situação seria possível quando a ação já fosse originariamente ajuizada pelo Ministério Público ou mesmo qualquer outro ente legitimado para ajuizar uma ação coletiva.

A outra situação seria viabilizar a intervenção de tais entes em ação judicial originariamente ajuizada por indivíduo.

Nesse segundo caso, apresenta-se a segunda proposta do presente artigo: A criação de um incidente para que um desses entes participe do processo com vistas a viabilizar a coisa julgada in utilibus a todos aqueles que dependam daquela correção ou complementação da política pública questionada.

De pronto, essa atuação do Ministério Público em ação ajuizada por particular não é de todo desconhecida do sistema processual brasileiro, bastando lembrar a situação existente na ação penal privada subsidiária da pública, pois esta, originariamente ajuizada pelo Particular, tem no Ministério Público a atuação delineada no artigo 29 e 45 do Código de Processo Penal ${ }^{13}$, cabendo a

3 Art. 29. Será admitida ação privada nos crimes de ação pública, se esta não for intentada no prazo legal, cabendo ao Ministério Público aditar a queixa, repudiá-la e oferecer denúncia substitutiva, intervir em todos os termos do processo, fornecer elementos de prova, interpor recurso e, a todo tempo, no caso de negligência do querelante, retomar a ação como parte principal. Art. 45. A queixa, ainda quando a ação penal for privativa do ofendido, poderá ser aditada pelo Ministério Público, a quem caberá intervir em todos os termos subsequentes do processo. BRASIL. Decreto-Lei $n^{\circ} 3.689$, de 3 de outubro de 1941. Código de Processo Penal. Disponível em: <http://www.planalto.gov.br/ccivil_03/decreto-lei/ Del3689.htm>. Acesso em: 24 jun. 2015. 
ele acompanhar o processo e assumir no caso de inércia do particular.

\section{Do procedimento do incidente de coletiviza- ção de demanda individual}

E como seria o procedimento do incidente?

Reputam-se essenciais algumas questões para a proposta:

1) A configuração de interesse individual indisponível;

2) A necessidade de correção/complementação de política pública como causa de pedir;

3) A instauração do incidente, como não poderia deixar de ser, poderia ser requerida por quaisquer das partes, podendo, inclusive, ser instada de ofício pelo Juiz.

4) Para fins de segurança jurídica, essa ampliação da coisa julgada in utilibus deve ser objeto de decisão interlocutória específica por parte do magistrado, antes de proferir a sentença.

5) O juiz dessa causa deve ser prevento para todos os casos semelhantes eventualmente ajuizados pelo indivíduo.

6) Deve ser prevista fase conciliatória obrigatória, em que se incentive o diálogo efetivo entre as partes, garantindo, por exemplo, que a Administração proponha formas de resolução do problema.

7) A situação urgente e individual deve merecer autonomia processual.

8) Estabelecimento de prazo para o julgamento da demanda.

Os passos desse procedimento podem ser sintetizados da seguinte forma:

1) Caso o Juiz ou quaisquer das partes identifique que o pedido veicule interesse individual indisponível e que busque corrigir ou complementar determinada política pública, o Juiz pode instar pessoalmente o Ministério Público e Defensoria para que, analisando a questão, viesse a aditar o pedido inicial com vistas a solicitar que eventual concessão do pedido atinja todas as pessoas que estejam na mesma situação.

2) Como outra entidade legitimidade também venha a ter interesse, seria recomendável tam- bém a publicação de editais, segundo as regras do CPC para eventual participação dessas entidades.

3) Em respeito ao princípio do contraditório, dever-se-ia instaurar um pequeno incidente com alguns objetivos específicos.

4) Caberia a parte pleiteante demonstrar:

a. A configuração do interesse público indisponível;

b. A necessidade de correção/complementação de política pública;

c. As vantagens da ampliação da coisa julgada in utilibus.

d. A petição necessariamente deve indicar os eventuais impactos sociais, econômicos e financeiros da decisão.

5) A parte ré nesse incidente, muito provavelmente o estado, poderá contestar os dados apresentados pelo suscitante, bem como ela própria poderia propor as modificações, além de propor verdadeiro planejamento a respeito do melhor cumprimento do pedido, ou a sua impossibilidade ou mesmo a sua regulamentação. Ademias, se achar interessante, deve refutar a necessidade de ampliação da coisa julgada in utilibus bem como avaliar os impactos trazidos pela parte suscintante

1) O juiz deve marcar uma audiência de conciliação, especialmente dedicada: 1) para avaliação dos impactos da decisão; 2) Possibilidade de ampliação da coisa julgada in utilibus.

2) Deferido o pedido, o juiz prosseguiria com a participação de ente coletivo.

3) Esse juiz, responsável pela instauração do incidente, seria então prevento para todas as ações equivalentes àquela ação originariamente ajuizada.

Daí vem outra pergunta: Essa reunião de ações tem atualmente respaldo legal, pois haveria conexão entre elas?

Pelo que consta da interpretação do artigo 103 do Código de Processo Civil, essas ações não são conexas, porque as causas de pedir não são comuns, pois cada um dos autores pleiteia direito próprio. Veja a respeito a lição de Cândido Rangel Dinamarco:

A coincidência entre os elementos objetivos das demandas, para determinar a conexidade 
juridicamente relevante, deve ser coincidência quanto aos elementos concretos da causa de pedir ou quanto aos elementos do pedido. A coincidência de elementos abstratos conduz à mera afinidade entre as demandas, que não chega a ser conexidade e não tem os mesmos efeitos desta. Há conexidade pelo petitum quando o bem da vida pleiteado é concretamente o mesmo - como se dá quando dois ou mais sujeitos postulam a posse ou domínio do mesmo imóvel ou quando ambos os cônjuges pedem a separação judicial. Não há conexidade só pela identidade de natureza do bem da vida (móvel, imóvel) ou pela coincidência na natureza do provimento jurisdicional postulado. Do mesmo modo, duas demandas são conexas pela causa de pedir quando os fatos narrados são os mesmos, ainda que só parcialmente coincidam. A mera coincidência dos fundamentos jurídicos não é todavia, suficiente para fazer com que duas causas sejam conexas (p. ex., milhares de funcionários públicos em litígio com o Estado por certo recálculo de vencimentos ou uma multidão de consumidores pleiteando indenização pelo defeito de dado produto).${ }^{14}$

Mas, como já mencionado pelo Autor, a situação daqueles que pleiteam determinado medicamento ou tratamento não abarcado pelo Estado, configura situação de afinidade de questões por um ponto comum de fato ou de direito, nos termos do artigo 46, inciso III do Código de Processo Civil ${ }^{15}$. No caso, todos os cidadãos devem demonstra que a ausência ou erro de determinada política pública está lhe causando prejuízos.

Assim, além da alteração legislativa relacionada ao próprio incidente, também as regras de prevenção deveriam ser modificadas com vistas a garantir a prevenção do juízo nas hipóteses de ações individuais que guardem entre si afinidade de questões por um ponto comum de fato ou de direito. Certamente, essa regra não gera muitos problemas se a decisão judicial for pelo reconhecimento do pedido. Todavia, algum problema pode ser constatado no caso de improcedência do pedido. Nesse caso, a situação ideal seria a busca pela uniformidade da decisão a respeito da política pública prevalecer em face da fa-

4 DINAMARCO, Candido Rangel. Instituições de direito processual civil. São Paulo: Malheiros, v. 2. p. 150.

15 É uma conexidade degradada, de intensidade menor, caracterizada por um causa petendi parcialmente igual, mas não chega a ponto de ser a mesma [...] Exemplo típico é o caráter lesivo de um medicamento, que pode ser alegado por um grande número de consumidores, mas cada um tendo também o ônus de expor como e em que medida o produto lhe causou danos e quais foram esses. DINAMARCO, Candido Rangel. Instituições de direito processual civil. São Paulo: Malheiros, v. 2. p. 151. culdade do indivíduo de buscar outro juízo, todavia, não se nega que isso mereça uma reflexão mais aprofundada.

E, como fica a situação daquele que ajuizou originariamente a ação? Aquele que ajuizou a ação poderia ter acesso ao direito àquele determinado medicamento e/ ou tratamento não previsto na política pública, desde que comprovasse a urgência do pedido, e da mesma forma, outras pessoas que estivessem na mesma situação fática. O Juiz, exemplificadamente, poderia ordenar que Administração estabeleça uma "fila” por ordem cronológica ou de necessidade a depender da hipótese para cumprimento da decisão. Além disso, aqueles que não estivessem em situação de urgência teriam suspensos seus pedidos.

E, como as demais pessoas comprovariam a sua situação? Como em qualquer ação de caráter coletivo, caberia ao titular do direito comprovar a sua situação ou perante a Administração, caso esta já tenha regulado a situação, ou em sede de execução provisória ou definitiva, a depender da hipótese ${ }^{16}$.

Uma última questão ainda seria: Haveria algum

16 PROCESSUAL CIVIL. LEGITIMIDADE. EXECUÇÃO INDIVIDUAL. SENTENÇA COLETIVA. MEMBROS DE TODA A CATEGORIA. 1. O sindicato, como substituto processual, tem legitimidade para defender judicialmente interesses coletivos de toda a categoria, e não apenas de seus filiados, sendo dispensável a juntada da relação nominal dos filiados e de autorização expressa. 2. Assim, a formação da coisa julgada nos autos de ação coletiva deve beneficiar todos os servidores da categoria, e não apenas aqueles que constaram do rol de substituídos. Precedentes.3. Agravo regimental não provido. (Grifo nosso). BRASIL. Superior Tribunal de Justiça. Agravo Regimental no Recurso Especial. AgRg no REsp 1195607 RJ 2010/0096075-1. Segunda Turma. Recorrente: Rosangela de Abreu Marques. Recorrido: Instituto Nacional do Seguro Social. Relator: Min. Castro Meira. Brasília, 10 de abril de 2012. Disponível em: <http://stj.jusbrasil.com.br/jurisprudencia/21558593/ agravo-regimental-no-recurso-especial-agrg-no-resp1195607-rj-2010-0096075-1-stj>. Acesso em: 24 jun. 2015. [...] I - Nas execuções individuais, o prazo prescricional é o quinquenal, próprio das ações coletivas, contado a partir do trânsito em julgado da sentença coletiva, nos termos do precedente firmado no julgamento dos recursos especiais 1.275.215/RS e 1.276.376/PR, Dje 1º.2.2012. II - Mantida a decisão que considerou prescrita a pretensão executiva.III. Agravo regimental não provido. BRASIL. Superior Tribunal de Justiça. Agravo Regimental no Agravo em Recurso Especial. AgRg no AREsp 82496 PR 2011/0199370-8. Quarta Turma. Agravante: Ivamir Ruberval Nocetti e outros. Agravado Banco Itaú. Relator: Min. Marco Buzzi. Brasília, 06 de março de 2012. Disponível em: <http://stj.jusbrasil. com.br/jurisprudencia/21420097/agravo-regimental-noagravo-em-recurso-especial-agrg-no-aresp-82496-pr2011-0199370-8-stj/inteiro-teor-21420098>. Acesso em: 24 jun. 2015. 
limite territorial em relação a eficácia da decisão? Aqui, sugere-se que a regra a ser seguida seja mesma das Ações Civis Públicas, qual seja, a limitação territorial da eficácia da decisão ${ }^{17}$, sendo que havendo divergência entre decisões de Estados diferente, o Superior Tribunal de Justiça poderia ser chamado a decidir,

E quais seriam as vantagens desse incidente?

Reunindo todos aqueles que busquem o mesmo bem da vida em face de uma determinada política pública, o juiz teria condições para avaliar de maneira global a referida questão, podendo, com melhor conhecimento de causa, estabelecer verdadeiro diálogo institucional com o Poder Executivo. Da parte do Poder executivo, este poderia expor com maior abrangência a justificativa pela escolha de determinada opção técnica daquela política pública, bem como indicar o impacto econômico da decisão, por exemplo. Com isso, estará sob a responsabilidade do juiz a avaliação da decisão judicial tendo em conta o real ou potencial impacto da decisão no orçamento público e nas escolhas previamente feitas pelo Poder Executivo.

E o mais importante, reunindo ou tendo possibilidade de reunir todos os cidadãos com aquele problema, o argumento da quebra da isonomia pelo próprio Poder Judiciário poderia ser mitigado, pois a Administração, sob ordem do Poder Judiciário, uma vez que a questão

17 [... 2. A presente ação civil pública foi proposta com base nos "interesses individuais homogêneos" do consumidores/ usuários de serviço bancário, tutelados pela Lei no 8.078, em seu art. 81, parágrafo único, inciso III, ou seja, aqueles entendidos como decorrentes de origem comum, consoante demonstrado pelo Tribunal de origem, motivo pelo qual não há falar em falta de legitimação do Ministério Público para propor a ação. 3. A análise quanto a validade de cláusula contratual "padrão", em contratos de mútuo oferecidos aos consumidores, estabelecendo a comissão de permanência, esbarra na verificação do conteúdo do "contrato tipo" impugnado, especialmente quando é incontroverso a existência de cláusulas que determinam a cobrança de outros encargos moratórios cumulados para o período de inadimplência. Incidência da Súmula 5/STJ. 4. A sentença proferida em ação civil pública fará coisa julgada "erga omnes" nos limites da competência do órgão prolator da decisão, nos termos do art. 16 da Lei n. 7.347/85, alterado pela Lei n. 9.494/97, não havendo falar em inépcia da inicial. Precedentes.[...] (grifo nosso). BRASIL. Superior Tribunal de Justiça. Recurso Especial. REsp 600711 RS 2003/0184448-0. Quarta Turma. Recorrente: Banco Lloyds TSB. Recorrido: Ministério Público do Estado do Rio Grande do Sul. Relator: Min. Luís Felipe Salomão, 18 de novembro de 2010. Disponível em: <http://stj.jusbrasil. com.br/jurisprudencia/17628713/recurso-especial-resp-600711-rs-2003-0184448-0/inteiro-teor-17628714>. Acesso em: 24 jun. 2015. está judicializada e "coletivizada", poderia convocar todos aqueles na mesma situação e estabelecer uma lista por ordem de antiguidade e/ou necessidade.

Uma última questão procedimental: $\mathrm{O}$ juiz deveria ficar indefinidamente com o processo em curso, decidindo apenas a respeito das questões individuais urgentes? Aqui, deve-se sugerir o estabelecimento de um prazo e da prioridade de julgamento, da mesma forma que estabelecido no denominado incidente de resolução de demandas repetitivas, como se verá abaixo. Nesse prazo, o juiz deveria estabelecer as premissas para o cumprimento de sua decisão, caso a sentença seja favorável.

\section{Da análise da proposta em face do denomi- nado incidente de resolução de demandas repetitivas}

Por fim, fica uma última questão: Há algum regramento semelhante no Código de Processo Civil recentemente aprovado?

O Novo Código estabeleceu nos artigos $976^{18}$ e seguintes o denominado incidente de resolução de demandas repetitivas, que, segundo a exposição de motivos, tem as seguintes características:

[...] criou-se, com inspiração no direito alemão, o já referido incidente de Resolução de Demandas Repetitivas, que consiste na identificação de processos que contenham a mesma questão de direito, que estejam ainda no primeiro grau de jurisdição, para decisão conjunta.

O incidente de resolução de demandas repetitivas é admissível quando identificada, em primeiro grau, controvérsia com potencial de gerar multiplicação expressiva de demandas e o correlato risco da coexistência de decisões conflitantes.

É instaurado perante o Tribunal local, por iniciativa do juiz, do MP, das partes, da Defensoria Pública ou pelo próprio Relator. O juízo de admissibilidade e de mérito caberão ao tribunal pleno ou ao órgão especial, onde houver, e a extensão da eficácia da decisão acerca da tese jurídica limita-se à área de competência terri-

18 Art. 976. É cabível a instauração do incidente de resolução de demandas repetitivas quando houver, simultaneamente:I - efetiva repetição de processos que contenham controvérsia sobre a mesma questão unicamente de direito;II - risco de ofensa à isonomia e à segurança jurídica. BRASIL. Lei no 13.105, de 16 de março de 2015. Código de Processo Civil. Disponível em: <http://www.planalto.gov.br/ ccivil_03/_Ato2015-2018/2015/Lei/L13105.htm>. Acesso em: 24 jun. 2015. 
torial do tribunal, salvo decisão em contrário do STF ou dos Tribunais superiores, pleiteada pelas partes, interessados, MP ou Defensoria Pública. Há a possibilidade de intervenção de amici curiae.

O incidente deve ser julgado no prazo de seis meses, tendo preferência sobre os demais feitos, salvo os que envolvam réu preso ou pedido de habeas corpus.

O recurso especial e o recurso extraordinário, eventualmente interpostos da decisão do incidente, têm efeito suspensivo e se considera presumida a repercussão geral, de questão constitucional eventualmente discutida.

Enfim, não observada a tese firmada, caberá reclamação ao tribunal competente ${ }^{19}$.

Chama a atenção ainda a regra prevista no artigo 983 do referido Código, o qual, inegavelmente, instaurará diálogo com as instâncias oficiais.

Art. 983. O relator ouvirá as partes e os demais interessados, inclusive pessoas, órgãos e entidades com interesse na controvérsia, que, no prazo comum de 15 (quinze) dias, poderão requerer a juntada de documentos, bem como as diligências necessárias para a elucidação da questão de direito controvertida, e, em seguida, manifestar-se-á o Ministério Público, no mesmo prazo.

$\$ 1$ ara instruir o incidente, o relator poderá designar data para, em audiência pública, ouvir depoimentos de pessoas com experiência e conhecimento na matéria.

$\$ 2^{\circ}$ Concluídas as diligências, o relator solicitará dia para o julgamento do incidente. ${ }^{20}$

Esse incidente poderia auxiliar a conferir ao Tribunal a visão global que exige a Doutrina para que o Judiciário intervenha em determinada política pública, todavia, há algumas questões que o referido incidente não supera, tais como:

1) O referido incidente somente pode ser instaurado se a controvérsia for de direito, e, como se sabe, em muitos dos casos de intervenção do Poder Judiciário em determinada política

19 BRASIL. Congresso Nacional. Senado Federal. Anteprojeto do novo Código de Processo Civil: comissão de juristas instituída pelo Ato do Presidente do Senado Federal no 379, de 2009, destinada a elaborar Anteprojeto de Novo Código de Processo Civil. Brasília: Senado Federal, 2010. Disponível em: <http://www.senado.gov.br/senado/novocpc/pdf/Anteprojeto.pdf>. Acesso em: 24 jun. 2015.

20 BRASIL. Lei no 13.105, de 16 de março de 2015. Código de Processo Civil. Disponível em: <http://www.planalto. gov.br/ccivil_03/_Ato2015-2018/2015/Lei/L13105.htm>. Acesso em: 24 jun. 2015. pública, especialmente aquelas que exigem de tratamento médico ou fornecimento de medicamento, tanto a parte autora quando a parte ré exigirão a produção de prova. No caso do autor, este deve provar que precisa do medicamento. Por outro lado, a defesa do órgão ou entidade pública gira em torno da reserva do possível. E, como já reconhecido pelo Superior Tribunal de Justiça, a adoção da tese da reserva do possível depende de comprovação extremamente rigorosa ${ }^{21}$ que vai ou deve levar em conta o impacto financeiro daquela determinada demanda. Além disso, a tese jurídica relacionada à possibilidade ou não do Poder Judiciário intervir em política pública já está razoavelmente sedimentada, cabendo apenas definir os parâmetros para sua atuação.

2) A proposta do presente artigo exige, para fins de instauração do incidente, que a parte apenas levante o eventual impacto da decisão, cabendo a concretização do direito pleiteado em favor do cidadão apenas ao tempo da execução do julgado.

3) Por outro lado, na proposta aqui mencionada, o juiz é realmente o diretor do processo e terá condições de exercer a denominada parcialidade positiva ${ }^{22}$, podendo funcionar como verdadeiro interlocutor para a melhor condução do problema posto em juízo e que atinge um número considerável de pessoas.

21 [...] não havendo comprovação objetiva da incapacidade econômico-financeira da pessoa estatal, inexistirá empecilho jurídico para que o Judiciário determine a inclusão de determinada política pública nos planos orçamentários do ente político. BRASIL. Superior Tribunal de Justiça. Recurso Especial. REsp 1041197 MS 2008/0059830-7. Segunda Turma. Recorrente: Estado de Mato Grosso do Sul. Recorrido: Ministério Público do Estado de Mato Grosso do Sul. Relator: Min. Humberto Martins, 25 de agosto de 2009. Disponível em: <http://stj.jusbrasil. com.br/jurisprudencia/6909418/recurso-especial-resp-1041197-ms-2008-0059830-7/inteiro-teor-12701279>. Acesso em: 24 jun. 2015.

22 SOUZA, Artur Cézar de. A parcialidade positiva do juiz. São Paulo: RT, 2008. p. 202. A parcialidade positiva impõe que $\mathrm{o}$ juiz pondere de forma adequada e previamente à tomada de decisões todos os interesses juridicamente relevantes, que o juiz possa reconhecer as diferenças sociais, culturais, econômicas, psicológicas, bem como a carga ideológica neogloibalizante que manipula os resultados do próprio process. 
4) Além disso, no incidente previsto pelo novo Código de Processo Civil, dado o seu caráter restrito a questão de direito, não está prevista qualquer possibilidade de conciliação. $\mathrm{Na}$ proposta aqui delineada, instaurado o referido incidente, podem haver várias reuniões ou mesmo o verdadeiro incentivo para que termos de ajustamento de condutas sejam celebrados, sendo inegável o poder desses termos para modificar políticas públicas em curso.

5) Além disso, na proposta prevista pelo novo Código de Processo Civil não há a previsão de manutenção da possibilidade do indivíduo solicitar tutelas de urgência, muito embora preveja com absoluto acerto, prazo para julgamento do incidente, bem como prioridade de julgamento.

6) Não se nega que na proposta aqui desenhada, o juiz, além de resolver pela intervenção em determinada política pública, poderá, no limite, passar a exercer verdadeiro papel de gestor publico. Mas, não é isso que acaba ocorrendo em algumas hipóteses, com o problema do juiz não ter a visão global da questão? Na proposta aqui iniciada, o risco de ocorrer o prejuízo do cidadão, que pode não ser beneficiado pela decisão, seja porque não ajuizou ação, ou mesmo estar sujeito a outro juiz que pensa de maneira diferente, será reduzido.

7) Com a proposta aqui delineada, o juiz, mais do que resolver episodicamente o caso de um determinado particular em face do Estado, terá a oportunidade de tentar efetivamente resolver o problema dialogando com os interessados daquela determinada política pública. Enfim, se não se nega mais a possibilidade de intervenção do Poder Judiciário nas políticas públicas, que esse poder envide todos os esforços necessários para efetivamente resolver o problema com a visão global e não apenas particular daquele determinado caso levado ao seu conhecimento.

Algo semelhante à proposta do presente artigo estava previsto nos artigos 333 e seguintes:

"Art. 333. Atendidos os pressupostos da relevância social e da dificuldade de formação do litisconsórcio, o juiz, a requerimento do Ministério Público ou da Defensoria Pública, ouvido o autor, poderá converter em coletiva a ação individual que veicule pedido que:

I - tenha alcance coletivo, em razão da tutela de bem jurídico difuso ou coletivo, assim entendidos aqueles definidos pelo art. 81, parágrafo único, incisos I e II, da Lei no setembro de 1990 (Código de Defesa do Consumidor), e cuja ofensa afete, a um só tempo, as esferas jurídicas do indivíduo e da coletividade;

II - tenha por objetivo a solução de conflito de interesse relativo a uma mesma relação jurídica plurilateral, cuja solução, por sua natureza ou por disposição de lei, deva ser necessariamente uniforme, assegurando-se tratamento isonômico para todos os membros do grupo.

$\$ 1^{\circ}$ Além do Ministério Público e da Defensoria Pública, podem requerer a conversão os legitimados referidos no art. $5^{\circ}$ da Lei no ${ }^{\circ}$ 7.347, de 24 de julho de 1985, e no art. 82 da Lei no 8.078, de 11 de setembro de 1990 (Código de Defesa do Consumidor).

$\$ 2^{\circ}$ A conversão não pode implicar a formação de processo coletivo para a tutela de direitos individuais homogêneos.

$\$ 3$ Não se admite a conversão, ainda, se:

I - já iniciada, no processo individual, a audiência de instrução e julgamento; ou

II - houver processo coletivo pendente com o mesmo objeto; ou

III - o juízo não tiver competência para o processo coletivo que seria formado.

$\$ 4^{\circ}$ Determinada a conversão, o juiz intimará o autor do requerimento para que, no prazo fixado, adite ou emende a petição inicial, para adaptá-la à tutela coletiva.

$\$ 5$ 을 Havendo aditamento ou emenda da petição inicial, o juiz determinará a intimação do réu para, querendo, manifestar-se no prazo de 15 (quinze) dias.

\$ 60 O autor originário da ação individual atuará na condição de litisconsorte unitário do legitimado para condução do processo coletivo.

$\$ 7$ o $\mathrm{O}$ autor originário não é responsável por nenhuma despesa processual decorrente da conversão do processo individual em coletivo.

$\$ 8^{\circ}$ Após a conversão, observar-se-ão as regras do processo coletivo.

$\$ 9$ o A conversão poderá ocorrer mesmo que o autor tenha cumulado pedido de natureza estritamente individual, hipótese em que o processamento desse pedido dar-se-á em autos apartados.

$\$ 10$. O Ministério Público deverá ser ouvido 
sobre o requerimento previsto no caput, salvo quando ele próprio o houver formulado." ${ }^{23}$

Diferentemente do incidente de resolução de demandas repetitivas, o presente incidente alcançaria a própria tutela do bem jurídico de natureza difusa implicaria em decisão uniforme em caso das relações plurilaterais. $\mathrm{O}$ juiz, em tais hipóteses, estaria autorizado a analisar a questão fática em torno da qual a discussão giraria em torno. Especialmente a previsão do artigo 333, inciso II se aproximaria da proposta aqui desenhada, pois a conversão seria admitida mesmo que o bem jurídico não fosse difuso ou coletivo.

Ocorre que tal dispositivo foi vetado com base nas seguintes razões:

Da forma como foi redigido, o dispositivo poderia levar à conversão de ação individual em ação coletiva de maneira pouco criteriosa, inclusive em detrimento do interesse das partes. $\mathrm{O}$ tema exige disciplina própria para garantir a plena eficácia do instituto. Além disso, o novo Código já contempla mecanismos para tratar demandas repetitivas. No sentido do veto manifestou-se também a Ordem dos Advogados do Brasil - OAB. ${ }^{24}$

Veja que não houve propriamente a repulsa do mérito da proposta, mas apenas a indicação de que tal conversão mereceria disciplina própria. E o presente artigo tem por objetivo, justamente, colaborar e enfatizar a necessidade de que a legislação brasileira admita a conversão da ação individual em coletiva nas hipóteses de direitos indisponíveis que interfiram em uma determinada política pública.

\section{Considerações finais}

Como visto acima, a proposta do presente artigo era avaliar a possibilidade de "coletivização" de uma determinada demanda judicial que busca corrigir/complementar determinada política pública. No caso, trabalhou-se com a hipótese de ação individual que buscasse determinado medicamento ou tratamento médico não previsto pela política pública.

Viu-se que mesmo na existência de vários indivíduos com a mesma necessidade, esses interesses não configurariam interesses individuais homogêneos a justificar o ajui-

23 BRASIL. Mensagem $n^{\circ}$ 56, de 16 de março de 2015. Disponível em: <http://www.planalto.gov.br/ccivil_03/_ato20152018/2015/Msg/VEP-56.htm>. Acesso em: 24 jun. 2015.

24 BRASIL. Mensagem no 56, de 16 de março de 2015. Disponível em: <http://www.planalto.gov.br/ccivil_03/_ato20152018/2015/Msg/VEP-56.htm>. Acesso em: 24 jun. 2015. zamento de ação coletiva. Da mesma forma, eventuais ações individuais buscando o mesmo objeto não seriam conexas, autorizado quando muito a formação de litisconsórcio por terem em afinidade de questões de fato ou de direito.

Dessa forma, para o juiz ter a necessária visão global da situação evitando ofensas ao princípio da isonomia é que se propôs o denominado incidente de coletivização de demandas individuais que busquem corrigir ou complementar políticas públicas.

A presente proposta, então, faz com que a ação individual funcione como agente provocador da ampliação da coisa julgada in utilibus.

Não se propõe aqui a adoção do critério da class action, ou seja, não se propôs que o indivíduo tenha atribuição de defender a coletividade, até porque, como se viu, não se trata de direito coletivo.

Aqui, o que se propõe é que reconhecido os pressupostos acima desenvolvidos, um ente com legitimidade para ação coletiva participe do processo na defesa de uma reunião de interesses individuais indisponíveis em que seus autores busquem a correção/complementação de determinada política pública.

Com isso, a visão global de toda política pública seria mais facilmente alcançável, sendo que o benefício a outros que estejam na mesma situação dependeria apenas da execução do comando, ou mesmo de regulamentação pela Administração, e não necessariamente do ajuizamento de uma nova ação. Além disso, aquele juiz seria prevento para todas as demais ações para aquela mesma competência territorial, sendo que essa proposta de alteração da regra de prevenção deve ser ainda objeto de alguma reflexão.

Inegavelmente, esse incidente poderia reduzir o número de processos em curso, e também o risco de decisões conflitantes a respeito da mesma política pública, bem como centralizaria o debate a respeito da intervenção ou não daquela determinada política pública, podendo beneficiar, inclusive, aqueles que não ajuizariam demandas buscando aquele bem da vida.

Note-se que a presente proposta decorre de um pressuposto inquestionável: A intervenção do Poder Judiciário nas políticas públicas como um caminho sem volta. Então, se assim é, que esse juiz decida/busque decidir sempre tendo em vista o impacto social e econômico da demanda, fortalecendo, dessa forma, seu papel no diálogo com as instituições. Possibilitar, então, a ampliação da coisa julgada in utilibus para as demandas que veiculem direitos individuais indisponíveis em ações que busquem 
corrigir/complementar determinada política pública poderia ser uma saída, até porque reduziria a possibilidade de ofensa ao princípio da isonomia pelo próprio Poder Judiciário.

Enfim, longe de propor qualquer resposta mágica, fica a reflexão com vistas a subsidiar o debate a respeito da necessidade de visão global do Juiz ao decidir a respeito de questões que envolvam políticas públicas, sendo que o veto a proposta do artigo 333, inciso I do Novo Código de Processo Civil não pode ser um empecilho absoluto a discussão de propostas como a que ora se apresenta.

\section{Referências}

BRASIL. Congresso Nacional. Senado Federal. Anteprojeto do novo Código de Processo Civil: Comissão de Juristas instituída pelo Ato do Presidente do Senado Federal n ${ }^{\circ}$ 379, de 2009, destinada a elaborar Anteprojeto de Novo Código de Processo Civil. Brasília: Senado Federal, Presidência, 2010. Disponível em: <http://www.senado.gov. $\mathrm{br} / \mathrm{senado} /$ novocpc/pdf/Anteprojeto.pdf $>$. Acesso em: 24 jun. 2015.

BRASIL. Decreto-Lei no 3.689, de 3 de outubro de 1941. Código de Processo Penal. Disponível em: <http://www. planalto.gov.br/ccivil_03/decreto-lei/Del3689.htm>. Acesso em: 24 jun. 2015.

BRASIL. Lei no 4.717, de 29 de junho de 1965. Regula a ação popular. Disponível em: <http://www.planalto.gov. br/ccivil_03/LEIS/L4717.htm>. Acesso em: 24 jun. 2015.

BRASIL. Lei no 8.078, de 11 de setembro de 1990. Dispõe sobre a proteção do consumidor e dá outras providências. Disponível em: <http://www.planalto.gov.br/ccivil_03/ leis/18078.htm>. Acesso em: 24 jun. 2015.

BRASIL. Lei no 13.105, de 16 de março de 2015. Código de Processo Civil. Disponível em: <http://www.planalto. gov.br/ccivil_03/_Ato2015-2018/2015/Lei/L13105.htm>. Acesso em: 24 jun. 2015.

BRASIL. Mensagem $n^{\circ}$ 56, de 16 de março de 2015. Disponível em: <http://www.planalto.gov.br/ccivil_03/_ato20152018/2015/Msg/VEP-56.htm>. Acesso em: 24 jun. 2015.

BRASIL. Superior Tribunal de Justiça. Agravo Regimental no Agravo em Recurso Especial. AgRg no AREsp 82496 PR 2011/0199370-8. Quarta Turma. Agravante: Ivamir Ruberval Nocetti e outros. Agravado Banco Itaú. Relator: Min. Marco Buzzi. Brasília, 06 de março de 2012. Disponível em: <http://stj.jusbrasil.com.br/jurisprudencia/21420097/agravo-regimental-no-agravo-em-recurso-especial-agrg-no-aresp-82496-pr-2011-0199370-8-stj/inteiro-teor-21420098>. Acesso em: 24 jun. 2015.
BRASIL. Superior Tribunal de Justiça. Agravo Regimental no Recurso Especial. AgRg no REsp 1086805 RS 2008/0191648-9. Primeira Turma. Agravante: Estado do Rio Grande do Sul. Agravado: Ministério Público do Estado do Rio Grande do Sul. Relator: Min. Arnaldo Esteves Lima. Brasilia, 02 de agosto de 2011. Disponível em: <http://stj.jusbrasil.com.br/jurisprudencia/21082652/agravo-regimental-no-recurso-especial-agrg-no-resp-1086805-rs-2008-0191648-9-stj/inteiro-teor-21082653>. Acesso em: 24 jun. 2015.

BRASIL. Superior Tribunal de Justiça. Agravo Regimental no Recurso Especial. AgRg no REsp 1195607 RJ 2010/0096075-1. Segunda Turma. Recorrente: Rosangela de Abreu Marques. Recorrido: Instituto Nacional do Seguro Social. Relator: Min. Castro Meira. Brasília, 10 de abril de 2012. Disponível em: <http://stj.jusbrasil.com.br/ jurisprudencia/21558593/agravo-regimental-no-recurso-especial-agrg-no-resp-1195607-rj-2010-0096075-1-stj>. Acesso em: 24 jun. 2015.

BRASIL. Superior Tribunal de Justiça. Embargos de Declaração no Recurso Especial. EDcl no REsp 976021 MG 2007/0185192-0. Terceira Turma. Recorrente: UNIMED Uberlândia Cooperativa de Trabalho Médico. Recorrido: Ministério Público do Estado de Minas Gerais. Relator: Min(a). Nancy Andrighi. Brasília, 26 de abril de 2011. Disponível em: <http://sti.jusbrasil.com.br/jurisprudencia/19095056/embargos-de-declaracao-no-recurso-especial-edcl-no-resp-976021-mg-2007-0185192-0/inteiro-teor-19095057>. Acesso em: 24 jun. 2015.

BRASIL. Superior Tribunal de Justiça. Recurso em Mandado de Segurança. RMS N 24.197 - PR 2007/0112500-5. Primeira Turma. Recorrente: Ministério Público do Estado do Paraná. Recorrido: Estado do Paraná. Relator: Min. Luiz Fux. Brasília, 04 de maio de 2010. Disponível em: $<$ http://www.tjsp.jus.br/Download/EPM/pdf/STJ-Fornecimentomedicamentos-hepatite-prescricaoparticular. pdf $>$. Acesso em: 24 jun. 2015.

BRASIL. Superior Tribunal de Justiça. Recurso Especial. REsp 1041197 MS 2008/0059830-7. Segunda Turma. Recorrente: Estado de Mato Grosso do Sul. Recorrido: Ministério Público do Estado de Mato Grosso do Sul. Relator: Min. Humberto Martins, 25 de agosto de 2009. Disponível em: <http://stj.jusbrasil.com.br/jurisprudencia/6909418/ recurso-especial-resp-1041197-ms-2008-0059830-7/inteiro-teor-12701279>. Acesso em: 24 jun. 2015.

BRASIL. Superior Tribunal de Justiça. Recurso Especial. REsp 600711 RS 2003/0184448-0. Quarta Turma. Recorrente: Banco Lloyds TSB. Recorrido: Ministério Público do Estado do Rio Grande do Sul. Relator: Min. Luís Felipe Salomão, 18 de novembro de 2010. Disponível em: $<$ http://stj.jusbrasil.com.br/jurisprudencia/17628713/ recurso-especial-resp-600711-rs-2003-0184448-0/inteiro-teor-17628714>. Acesso em: 24 jun. 2015. 
BRASIL. Supremo Tribunal Federal. Medida Cautelar em Arguição de Descumprimento de Preceito Fundamental. ADPF 45 MC/DF. Plenário. Agravante: Partido da Social Democracia Brasileira. Agravado: Presidente da República. Relator: Min. Celso de Mello. Brasília, 29 de abril de 2004. Disponível em: <http://stf.jusbrasil.com.br/jurisprudencia/14800508/medida-cautelar-em-arguicao-de-descumprimento-de-preceito-fundamental-adpf-45-df-stf $>$. Acesso em: 24 jun. 2015.

DINAMARCO, Candido Rangel. Instituições de direito processual civil. São Paulo: Malheiros, v. 2.

GRINOVER, Ada Pellegrini. A tutela jurisdicional dos interesses difusos. Revista Brasileira de Direito Processual: RBDPro, Uberaba, v. 15, n. 59, p. 23-47, jul./set. 2007.

MEIRELLES, Hely Lopes. Mandado de segurança. 28. ed. São Paulo: Malheiros, 2005.

RODRIGUES, Marcelo Abelha. Ação civil pública. In: DIDIER JR., Fredie (Org.). Ações constitucionais. 6. ed. Salvador: Jus Podivm, 2012. p. 351-446.
SILVA, Virgílio Afonso da. O Judiciário e as políticas públicas: entre transformação social e obstáculo à realização dos direitos sociais. In: SOUZA NETO, Cláudio Pereira de; SARMENTO, Daniel. (Org.). Direitos sociais: fundamentação, judicialização e direitos sociais em espécies. Rio de Janeiro: Lúmen Júris, 2008. p. 587-599. Disponível em: <http://www.teoriaedireitopublico.com.br/pdf/2008-Judiciario_e_politicas_publicas.pdf $>$. Acesso em: 24 jun. 2015.

SOUZA NETO, Cláudio Pereira. A justiciabilidade dos direitos sociais: críticas e parâmetros. In: SOUZA NETO, Cláudio Pereira de; SARMENTO, Daniel. (Org.). Direitos sociais: fundamentos, judicialização e direitos sociais em espécie. Rio de Janeiro: Lumen Juris, 2008. p. 515-551.

SOUZA, Artur Cézar de. A parcialidade positiva do juiz. São Paulo: RT, 2008. 